\title{
Self-expandable metallic stenting as a bridge to elective surgery versus emergency surgery for acute malignant right-sided colorectal obstruction
}

\author{
Bing $\mathrm{Li}^{1,2+}{ }^{2}$, Shi-Lun Cai ${ }^{1,2+}$, Zhen-Tao Lv ${ }^{1,2 \dagger}$, Ping-Hong Zhou ${ }^{1,2}$, Li-Qing Yao ${ }^{1,2}$, Qiang Shi ${ }^{1,2}$, Zhi-Peng Qi ${ }^{1,2}$,
}

Di Sun ${ }^{1,2}$, Ayimukedisi Yalikong ${ }^{1,2}$, En-Pan $X_{u^{1,2}}$, Jian-Min $X^{3}$ and Yun-Shi Zhong ${ }^{1,2^{*}}$

\begin{abstract}
Background: The use of a self-expandable metallic stent (SEMS) as a bridge to surgery has increased for patients with obstructing colorectal cancer. However, relatively few reports have compared SEMS as a bridge to elective surgery for acute malignant obstruction of the right-sided colon (MORC) vs. emergency surgery (ES). This study aimed to evaluate the benefits of elective surgery after SEMS placement vs. ES for patients (including stage IV cases) with acute MORC.

Methods: Patients with acute MORC who underwent radical resection for a primary tumour from July 2008 to November 2016 at Zhongshan Hospital of Fudan University were retrospectively enrolled. Postoperative short-term outcomes, progression-free survival (PFS), and overall survival (OS) were compared between the SEMS and ES groups.

Results: In total, 107 patients with acute MORC (35 in the SEMS group and 72 in the ES group) were included for analysis. The Intensive Care Unit admission rate was lower (11.4\% vs. 34.7\%, $P=0.011)$, the incidence of complications was reduced ( $11.4 \%$ vs. $29.2 \%, P=0.042)$, and the postoperative length of hospitalisation was significantly shorter ( $8.23 \pm 6.50$ vs. $11.18 \pm 6.71$ days, $P=0.033$ ) for the SEMS group. Survival curves showed no significant difference in PFS $(P=0.506)$ or OS $(P=0.989)$ between groups. Also, there was no significant difference in PFS and OS rates between patients with stage II and III colon cancer. After colectomy for synchronous liver metastases among stage IV patients, the hepatectomy rates for the SEMS and ES groups were $85.7 \%$ and $14.3 \%$, respectively $(P=0.029)$. The hazard ratio for colectomy alone vs. combined resection was 3.258 ( $95 \% \mathrm{Cl} 0.858-12.370 ; P=0.041)$.

Conclusion: Stent placement offers significant advantages in terms of short-term outcomes and comparable prognoses for acute MORC patients. For synchronous liver metastases, SEMS placement better prepares the patient for resection of the primary tumour and liver metastasis, which contribute to improved survival.
\end{abstract}

Keywords: Right-sided colon cancer, Obstruction, Self-expandable metallic stent, Liver metastases

*Correspondence: zhongyunshi@yahoo.com

${ }^{\dagger}$ Bing Li, Shi-Lun Cai and Zhen-Tao Lv contribute equally to this paper

${ }^{1}$ Endoscopy Center, Zhongshan Hospital of Fudan University, 180 Fenglin

Road, Shanghai 200032, China

Full list of author information is available at the end of the article

\section{Background}

Colorectal cancer (CRC) is the fourth most commonly diagnosed cancer and the second leading cause of cancerrelated death in both males and females [1]. Approximately $8-13 \%$ of patients with advanced colon cancer present with an obstruction of the large bowel [2-4]. A 
self-expandable metallic stent (SEMS) is widely used for obstructive left-sided colon cancer to allow for an easy endoscopic approach to the lesion and to facilitate patient recovery from the acute status with reduced risks of postoperative complications and mortality [5-7]. However, fewer than $10 \%$ of reported cases of colonic stenting have involved the right colon [8].

Some studies have reported insertion of a SEMS for acute malignant obstruction of the right-sided colon (MORC) could benefit patients with severe comorbidities, advanced age, or complete obstruction $[9,10]$. Moreover, the technical success rate in experienced centres has improved to $>96 \%$, similar to that reported for stenting of distal colon lesions [11]. Thus, the present retrospective study included more cases than previous reports of the advantages of SEMS as a bridge to elective surgery as compared to emergency surgery (ES) for CRC patients with a proximal malignant obstruction of the large bowel. In addition, bowel obstruction is often accompanied by distant metastasis, as the liver is the most common site of CRC metastasis [4, 12]. Here, we report our experience and results with the use of colonic stenting of patients, including those with stage IV CRC, an area of the published data that remains severely limited. Therefore, the aim of the present study was to evaluate the benefits of elective surgery after SEMS placement vs. ES for patients (including stage IV cases) with acute MORC.

\section{Methods}

\section{Ethics statement}

The study protocol was approved by the Institutional Review Board of Zhongshan Hospital and conducted in accordance with the tenets of the Declaration of Helsinki. Informed consent was obtained from all patients prior to treatment. This retrospective observational study was conducted in accordance with the Strengthening the Reporting of Observational studies in Epidemiology (STROBE) guidelines [13].

\section{Patients}

The study cohort was limited to patients with acute rightsided bowel obstruction caused by malignant CRC who underwent radical resection for the primary tumour from July 2008 to November 2016 at Zhongshan Hospital of Fudan University (Shanghai, China). Right-sided colon cancer was defined as any tumour arising in the cecum, ascending colon, hepatic flexure or transverse colon. MORC was clinically defined as symptoms of abdominal pain, distension, vomiting, and no passage of stool or flatus, and radiologically defined as severe dilatation of the proximal colon due to suspected colon cancer by abdominal X-ray and/or contrast-enhanced computed tomography $(\mathrm{CT})$. Radical surgery was performed if no distant metastasis was observed either pre- or intra-operatively. However, if distant metastasis was found, radical resection was performed for the primary tumour, while sites of metastasis were treated by synchronous or two-stage resection, or other non-surgical treatments.

The patients were assigned to one of two groups: the ES group, which consisted of patients who underwent radical resection within $24 \mathrm{~h}$ after visiting the hospital and received no other treatments for primary causes, or the SEMS group, which consisted of patients who underwent colonic stent placement followed by surgery within 2 weeks after stent placement. The strategy to choose ES or SEMS placement as a bridge to surgery was mainly based on the following considerations: (1) the tumor locations differed significantly between the SEMS and ES groups, as stenting was not appropriate for an obstruction in the cecum; (2) low-pressure enema intestinal cleaning could be completed to facilitate stricture visualization and stent placement; (3) there were no signs of peritonitis or perforation in the SEMS group; (4) if ES was considered too risky or when the disease was very advanced and palliation was needed, stent placement as a bridge to surgery was considered; and (5) the final choice of treatment (ES or SEMS placement) was mostly dependent on a consensus among the surgeons, the endoscopists and the patient or patient's family.

\section{Procedure}

All stent placement procedures were performed by experienced endoscopists at the Endoscopy Centre of Zhongshan Hospital with experience and competence in both colonoscopy and fluoroscopic techniques and who performs colonic stenting on a regular basis. Briefly, the stent placement procedures consisted of four steps: (1) determining the site and aetiology of the acute bowel obstruction by colonoscopy combined with fluoroscopy; (2) a hydrophilic biliary guidewire was introduced through the tumour beyond the point of obstruction; (3) injection of water-soluble contrast medium proximally to the stricture; and (4) insertion and placement of suitable stents under fluoroscopic guidance. The immediate escape of air and liquid faeces through the stent indicated successful decompression.

Afterward, a series of examinations, including chest $\mathrm{X}$-ray, abdominal ultrasound or abdominal $\mathrm{CT}$, and blood tests, were performed. At 7 to 14 days after the colon obstruction was relieved, mechanical bowel preparation was performed using polyethylene glycol or sodium phosphate and one-stage surgery.

\section{Staging assessment and follow-up}

Pathological tumour-node-metastasis staging was performed in accordance with the guidelines of the Union 
for International Cancer Control, eighth edition. For all patients, routine clinical follow-up data were obtained. $\mathrm{CT}$, abdominal ultrasound, chest X-ray, and blood tests were performed every 3 months for the 1st year and then every 6 months thereafter. Colonoscopic surveillance was performed every 6 months for the 1st year and then once per year thereafter. Diagnoses of relapse and metastasis were based on imaging studies and biopsy, if necessary. The follow-up period was defined as the date of surgery to either the date of death or August 2018, whichever occurred first.

\section{Data collection and analysis}

In addition to clinicopathological data (i.e., age, sex, tumour characteristics, histopathology and surgical information), short-term postoperative outcomes and long-term prognoses were collected for analysis. The short-term postoperative outcomes mainly consisted of admission to the Intensive Care Unit (ICU), adverse events, and mortality within 30 days after surgery. The primary endpoints of long-term outcomes were progression-free survival (PFS) and overall survival (OS). Data were primarily obtained from medical records. For patients who had moved away, attempts were made to obtain outcome details by telephone contact with the patient or a family member.

Comparisons between groups were performed using the Student's $t$-test, chi-squared test, or Fisher's exact test and rank-sum test, as appropriate. Kaplan-Meier curves were constructed to analyse rates of survival, recurrence, and metastasis. The log-rank test was used to evaluate the significance of differences between curves. All statistical analyses were performed using SPSS for Windows, version 16.0. (SPSS Inc., Chicago, IL, USA). A probability $(P)$ value of $<0.05$ was considered statistically significant.

\section{Results}

\section{Baseline characteristics}

From July 2008 to November 2016, 107 patients with acute MORC (35 patients in the SEMS group and 72 in the ES group) underwent radical resection at Zhongshan Hospital. The median patient age was 66 (range 23-94) years. As shown in Table 1, there were no major differences in baseline and oncologic characteristics, with the exception of tumour location, between the SEMS and ES groups. No stent migration or perforation was observed, although one patient experienced re-obstruction after initial successful stenting. As of the last follow-up on August 2018, the overall median follow-up duration was 35 (range 0.1-120) months. Of the 107 patients, $13(12.1 \%)$ were lost to follow-up. However, there was no significant difference in the rate of patients lost to follow-up between the SEMS and ES groups (11.4\% [4/35] vs $12.5 \%$ [9/72], respectively; $P>0.99$ ).

\section{Characteristics of the procedures and postoperative short-term outcomes}

The characteristics of the surgical procedures and shortterm postoperative outcomes of the two groups are shown in Table 2. Although open surgery was the primary approach, laparoscopic procedures were performed more frequently in the SEMS group than the ES group (11.4\% vs. $0 \%$, respectively; $\mathrm{P}=0.010$ ). In regard to intraoperative findings, the incidence of ascites was greater in the ES group than the SEMS group (52.8\% vs. $20.0 \%$, respectively; $\mathrm{P}=0.001$ ), while perforation occurred in four (5.6\%) patients in the ES group. The need for intraoperative transfusion tended to be lower in the SEMS group than the ES group, but the difference was not statistically significant (2.9\% vs. $13.9 \%$, respectively; $\mathrm{P}=0.098)$. In the SEMS group, jejunostomy was performed for one patient, as partial duodenectomy was required due to intraoperative findings that the tumor had invaded the duodenum.

The postoperative ICU admission rate was significantly lower in the SEMS group than the ES group (11.4\% [4/35 vs. $34.7 \%[25 / 72]$, respectively; $P=0.011)$. Moreover, the complication rate was significantly lower in the SEMS group than the ES group (11.4\% [4/35] vs. 29.2\% [21/72], respectively; $P=0.042$ ). The most common postoperative complications in both groups were wound infection, pulmonary infection, and anastomotic leakage, but there was no significant difference in the incidence of complications between the two groups $(P>0.05)$. One patient in the ES group died due to multiple organ dysfunction syndrome on postoperative day 3. Moreover, the average duration of postoperative hospitalization was significantly shorter in the SEMS group than the ES group $(8.23 \pm 6.50$ vs. $11.18 \pm 6.71$ days, respectively; $P=0.033)$. After excluding tumors located in the cecum from the ES group, the characteristics of the surgical procedures and postoperative short-term outcomes of the two groups were compared. The results in Additional file 1: Table S1 show the advantages of stent placement in terms of lower ICU admission rate, reduced complication rates, and shorter postoperative hospital stays.

\section{Long-term outcomes of all populations in the SEMS and ES groups}

Kaplan-Meier curves of PFS for all patients are presented in Fig. 1a. The hazard ratio (HR) for PFS between the ES vs. SEMS groups was 1.235 (95\% confidence interval $[\mathrm{CI}]$ 0.674-2.263; $P=0.506)$. The 5-year PFS rate was greater in the SEMS group than the ES group $(54.0 \%$ [95\% CI $34.20-73.80 \%$ ] vs. $49.1 \%$ [95\% CI 35.97-62.23\%], respectively). The Kaplan-Meier curves of OS for all 
Table 1 Baseline and oncologic characteristics of the included patients

\begin{tabular}{|c|c|c|c|}
\hline & SEMS group $(n=35)$ & Emergency group $(n=72)$ & $\mathbf{P}$ \\
\hline \multicolumn{4}{|l|}{ Baseline characteristics } \\
\hline Age, y & & & 0.144 \\
\hline Median & 66 & 67 & \\
\hline Range & $24-92$ & $23-94$ & \\
\hline Sex, no. (\%) & & & 0.131 \\
\hline Male & $21(60.0 \%)$ & $32(44.4 \%)$ & \\
\hline Female & $14(40.0 \%)$ & $40(55.6 \%)$ & \\
\hline \multicolumn{4}{|l|}{ Comorbidity, no. (\%) } \\
\hline Hypertension & $10(28.6 \%)$ & $14(19.4 \%)$ & 0.288 \\
\hline Diabetes mellitus & $5(14.3 \%)$ & $11(15.3 \%)$ & 0.893 \\
\hline Cardiovascular disease & $3(8.6 \%)$ & $6(8.3 \%)$ & 1.000 \\
\hline Pulmonary disease & $2(5.7 \%)$ & $2(2.8 \%)$ & 0.596 \\
\hline Neurologic disease & $1(2.9 \%)$ & $2(2.8 \%)$ & 1.000 \\
\hline Other malignancy & $2(5.7 \%)$ & $3(4.2 \%)$ & 0.661 \\
\hline Renal disease & $0(0 \%)$ & $1(1.4 \%)$ & 1.000 \\
\hline \multicolumn{4}{|l|}{ Oncologic characteristics } \\
\hline Tumor size, mean $( \pm S D), \mathrm{cm}$ & $7.71 \pm 3.70$ & $5.85 \pm 2.58$ & 0.216 \\
\hline Tumor location, no. (\%) & & & 0.022 \\
\hline Cecum & $0(0 \%)$ & $11(15.3 \%)$ & \\
\hline Ascending colon & $12(34.3 \%)$ & $26(36.1 \%)$ & \\
\hline Hepatic flexure & $7(30.0 \%)$ & $17(23.6 \%)$ & \\
\hline Transverse colon & $16(45.7 \%)$ & $18(25.0 \%)$ & \\
\hline Pathology, no. (\%) & & & 0.893 \\
\hline Adenocarcinoma & $30(85.7 \%)$ & $61(84.7 \%)$ & \\
\hline Well differentiated & $2(5.7 \%)$ & $3(4.2 \%)$ & \\
\hline Moderately differentiated & $26(74.3 \%)$ & $54(75.0 \%)$ & \\
\hline Poorly differentiated & $2(5.7 \%)$ & $4(5.5 \%)$ & \\
\hline Mucinous & $5(14.3 \%)$ & $11(15.3 \%)$ & \\
\hline \multicolumn{4}{|c|}{ Lymphovascular involvement, no. (\%) } \\
\hline Yes & $13(37.1 \%)$ & $17(23.6 \%)$ & 0.144 \\
\hline No & $22(62.9 \%)$ & $55(76.4 \%)$ & \\
\hline pTNM stage & & & 0.240 \\
\hline$\|$ & $16(45.7 \%)$ & $31(43.1 \%)$ & \\
\hline III & $12(34.3 \%)$ & $34(47.2 \%)$ & \\
\hline IV & $7(20.0 \%)$ & $7(9.7 \%)$ & \\
\hline
\end{tabular}

SEMS self-expandable metal stents

patients are presented in Fig. 1b. The HR for OS between the ES and SEMS group was 0.995 (95\% CI 0.520-1.907; $P=0.989$ ). The 5-year OS rate was lower in the SEMS group than the ES group (56.0\% [95\% CI 36.40-75.60\%] vs. $61.6 \%$ [95\% CI $49.25-73.95 \%]$, respectively).

\section{Subgroup analyses based on tumor stage} Comparison of stage II and III disease between the SEMS and ES groups

During the follow-up period, disease progression, defined as local site recurrence and distant metastasis, was observed in 27 (29.0\%) patients with stage II and III disease. There was no significant difference in the distant metastasis rate between the SEMS and ES groups $(21.4 \%$ [6/28] vs. $18.5 \%$ [12/65], respectively; $P=0.740)$ or in the rate of local relapse $(7.1 \%[2 / 28]$ vs. $10.8 \%$ [7/65], respectively; $P=0.719)$. At the time of analysis, a total of 31 (33.3\%) patients died during the follow-up period. However, there was no significant difference in the mortality rate between the SEMS and ES groups $(32.1 \%[9 / 28]$ vs. $33.8 \%$ [22/65], respectively; $P=0.873)$ (Table 3). 
Table 2 Characteristics of the surgical procedures and postoperative short-term outcomes

\begin{tabular}{|c|c|c|c|}
\hline & SEMS group $(n=35)$ & Emergency group $(n=72)$ & $\mathbf{P}$ \\
\hline Operation method, no. (\%) & & & 0.010 \\
\hline Laparoscopy & $4(11.4 \%)$ & $0(0 \%)$ & \\
\hline Open & $31(88.6 \%)$ & $72(100 \%)$ & \\
\hline \multicolumn{4}{|l|}{ Operation findings, no. (\%) } \\
\hline Ascites & $7(20.0 \%)$ & $38(52.8 \%)$ & 0.001 \\
\hline Perforation & $0(0 \%)$ & $4(5.6 \%)$ & 0.301 \\
\hline Stoma formation & $1(2.9 \%)$ & $0(0 \%)$ & 0.327 \\
\hline Transfusion, no. (\%) & $1(2.9 \%)$ & $10(13.9 \%)$ & 0.098 \\
\hline Blood loss, mean $( \pm S D), \mathrm{ml}$ & $70.00 \pm 39.92$ & $77.22 \pm 50.94$ & 0.414 \\
\hline Operation time, mean $( \pm S D)$, min & $118.14 \pm 29.95$ & $147.14 \pm 43.77$ & 0.052 \\
\hline Positive margin, no. (\%) & $0(0 \%)$ & $0(0 \%)$ & / \\
\hline No. of retrieved LNs, mean ( $\pm S D$ ) & $21.09 \pm 9.89$ & $19.96 \pm 9.53$ & 0.766 \\
\hline No. of metastatic LNs, mean ( $\pm S D$ ) & $1.86 \pm 3.91$ & $1.89 \pm 2.69$ & 0.573 \\
\hline ICU stay, no. (\%) & $4(11.4 \%)$ & $25(34.7 \%)$ & 0.011 \\
\hline ICU stay time, mean $( \pm S D)$, day & $4.25 \pm 2.87$ & $3.96 \pm 2.81$ & 0.882 \\
\hline Postoperative complication, no. (\%) & $4(11.4 \%)$ & $21(29.2 \%)$ & 0.042 \\
\hline Wound infection & $1(2.9 \%)$ & $5(6.9 \%)$ & 0.661 \\
\hline Pneumonic infection & $2(5.7 \%)$ & $11(15.3 \%)$ & 0.217 \\
\hline Anastomotic leakage & $0(0 \%)$ & $3(4.2 \%)$ & 0.549 \\
\hline Gastric retention & $0(0 \%)$ & $1(1.4 \%)$ & 1.000 \\
\hline MODS & $0(0 \%)$ & $1(1.4 \%)$ & 1.000 \\
\hline AHF & $1(2.9 \%)$ & $0(0 \%)$ & 0.327 \\
\hline 30-days mortality, no. (\%) & $0(0 \%)$ & $1(1.8 \%)$ & 1.000 \\
\hline Hospital stay, mean ( $\pm S D$ ), day & $8.23 \pm 6.50$ & $11.18 \pm 6.71$ & 0.033 \\
\hline
\end{tabular}

SEMS self-expandable metal stents, LN lymph node, ICU intensive care unit, MODS multiple organ dysfunction syndrome, AHF acute heart failure

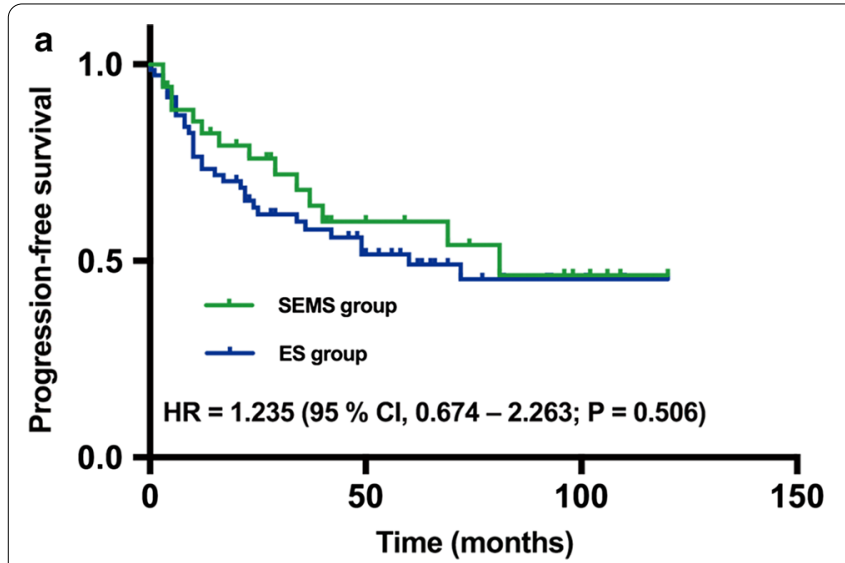

Fig. 1 a PFS and $\mathbf{b}$ OS outcomes of the SEMS and ES groups

PFS curves of the 93 patients with stage II and III disease are shown in Fig. 2a. As the HR for the ES vs. SEMS groups was 1.543 (95\% CI $0.774-3.075 ; P=0.253)$, the 5 -year PFS rate was $64.5 \%$ (95\% CI 43.53-85.47) for the SEMS group and 52.6\% (95\% CI 38.64-66.52) for

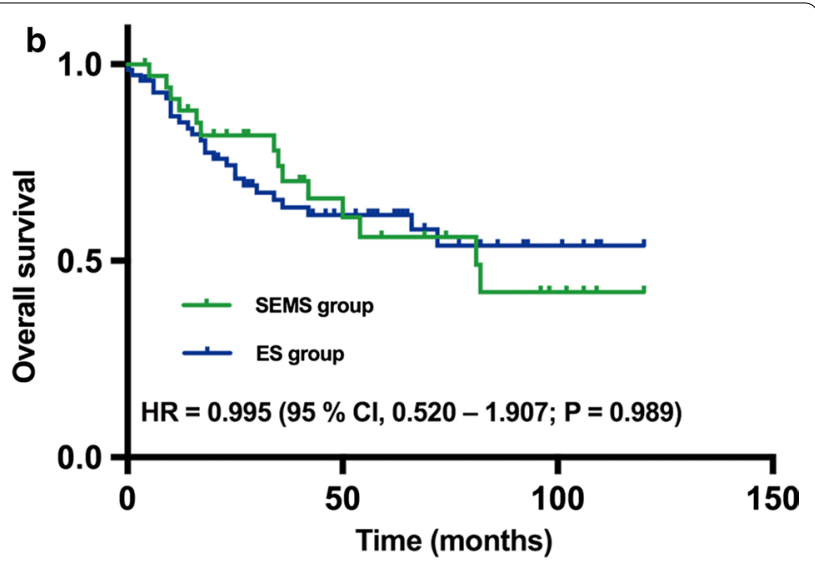

Time (months) the ES group. The Kaplan-Meier curves of OS are presented in Fig. 2b. The HR for the ES vs. SEMS group was 1.217 (95\% CI $0.559-2.646 ; P=0.619$ ), when the 5 -year OS rate was $68.2 \%$ (95\% CI 47.82-88.58) for the SEMS group and 64.2\% (95\% CI 51.46-76.94) for the ES group. 
Table 3 Long-term prognosis outcomes on patients with stage II and stage III disease in the SEMS group and emergency group

\begin{tabular}{|c|c|c|c|}
\hline & SEMS group $(n=28)$ & $\begin{array}{l}\text { Emergency } \\
\text { group } \\
(n=65)\end{array}$ & $\mathbf{P}$ \\
\hline $\begin{array}{l}\text { Distant metastasis, no. } \\
(\%)\end{array}$ & $6(21.4 \%)$ & $12(18.5 \%)^{\mathrm{a}}$ & 0.740 \\
\hline Liver & $1(3.6 \%)$ & $7(10.8 \%)$ & 0.427 \\
\hline Others & $5(17.9 \%)$ & $8(12.3 \%)$ & 0.522 \\
\hline Lungs & $2(7.1 \%)$ & $4(6.2 \%)$ & \\
\hline Peritoneum & $2(7.1 \%)$ & $3(4.6 \%)$ & \\
\hline Bone & $0(0 \%)$ & $1(1.5 \%)$ & \\
\hline Adrenal gland & $1(3.6 \%)$ & $0(0 \%)$ & \\
\hline Local site relapse, no. (\%) & $2(7.1 \%)$ & $7(10.8 \%)$ & 0.719 \\
\hline Death & $9(32.1 \%)$ & $22(33.8 \%)$ & 0.873 \\
\hline
\end{tabular}

a Two patient developed liver metastases and lungs metastases, and one patient developed liver metastases and bone metastases at the same time during follow-up

\section{Long-term outcomes of patients with stage IV disease}

Table 4 shows the clinicopathological characteristics and long-term prognostic outcome data of 14 patients with stage IV colon cancer in the two groups. The SEMS and ES groups both had seven CRC patients with synchronous liver metastases. After colectomy, the synchronous or two-stage hepatectomy rates was significantly greater in the SEMS group than the ES group (85.7\% [6/7] vs. $14.3 \%[1 / 7]$, respectively; $P=0.029)$. The remaining patients received chemotherapy, transcatheter arterial chemoembolisation or other palliative treatments.

To determine the advantages of different therapeutic regimens, survival outcomes of patients who underwent colectomy only vs. colectomy combined with hepatectomy were compared. Kaplan-Meier curves of OS are shown in Fig. 3. The data showed that median OS was superior for those who underwent combined resection as compared to colectomy alone (42 vs. 6 months, respectively), and the HR for colectomy only $v s$ combined resection was 3.258 (95\% CI 0.858-12.370; $\mathrm{P}=0.041$ ).

\section{Discussion}

In fact, since Campbell et al. reported the efficacy and safety of successful SEMS placement in MORC patients in 1997 [14], this technique has gained more and more attention. Repici et al. reported that the success rate for SEMS insertion for right-sided malignant colonic obstruction was $95 \%$ (20/21), with resolution of obstructive symptoms and no immediate complications in $85 \%$ of cases (17/20) [15]. Similarly, another recent study reported a success rate of $87.5 \%$ and symptom relief rate of $100 \%$ with no immediate complications [16]. In the present study, re-obstruction as a long-term complication occurred in only one patient. Collectively, these findings confirm the feasibility of SEMS placement for treatment of MORC.

Considering the higher morbidity and mortality rates as compared with elective surgery $[17,18]$, successful SEMS placement can provide sufficient preoperative preparation for patients with acute malignant colorectal obstruction prior to open or laparoscopic one-stage colectomy $[19,20]$. In the present study, 35 patients initially underwent SEMS placement as a bridge to elective surgery, while 72 patients underwent ES. Although open colectomy accounted for the majority of surgeries, laparoscopic colectomy, as opposed to ES, tended to be implemented in the SEMS group. As compared to open surgery, the advantages of laparoscopic approach include faster recovery and lower postoperative morbidity in the SEMS group. However, prior to 2016, colorectal surgeons at our center had limited experience with the laparoscopic approach, which explains the low
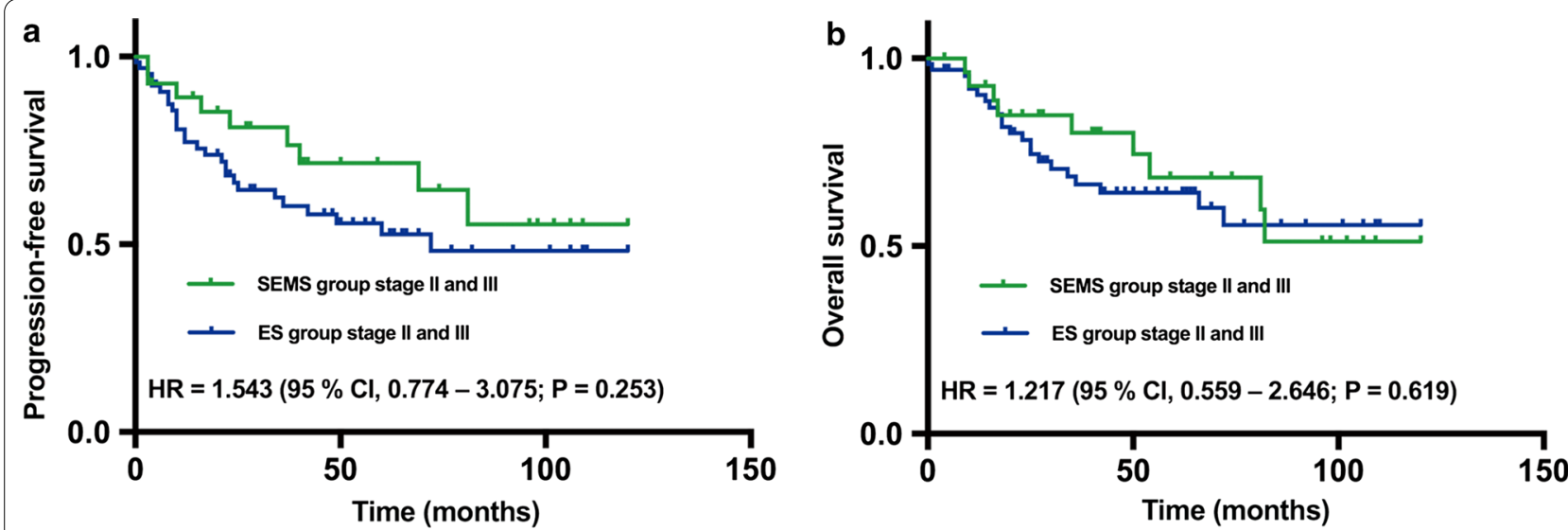

Fig. 2 a PFS and $\mathbf{b}$ OS of patients with stage II and III disease in the SEMS and ES groups 


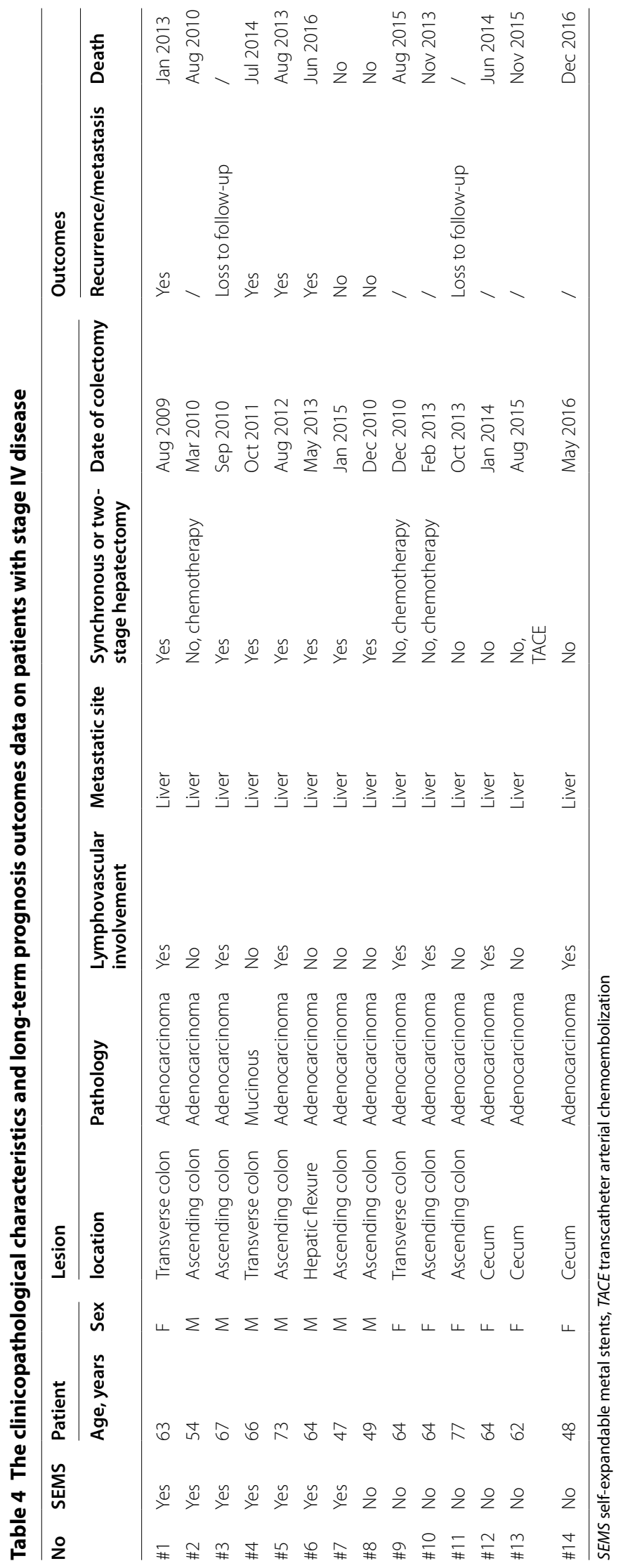




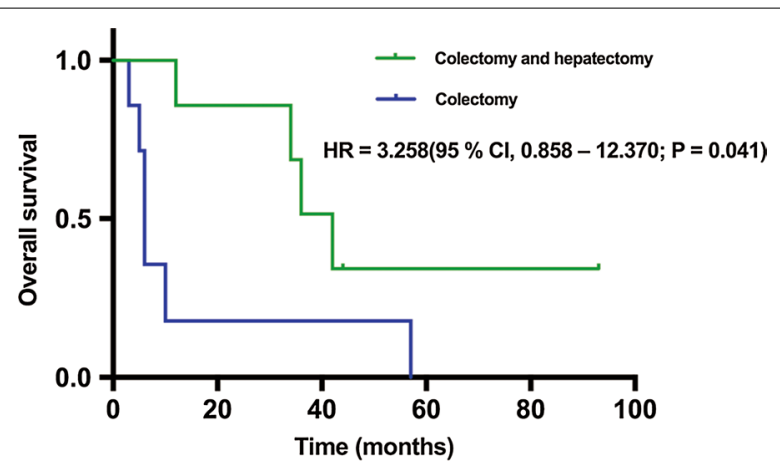

Fig. 3 OS curves of patients with stage IV disease treated by colectomy combined with hepatectomy and colectomy alone

rate of laparoscopic surgery, as it takes time to incorporate a new technology. In regard to the intra-operative findings, the incidence of ascites was greater in the ES group $(52.8 \%, 38 / 72)$ than the SEMS group (20.0\%, $7 / 35$ ), indicating that the physical status of patients in the SEMS group was better than that of the ES group. Likewise, in the present study, short-term outcomes were better in the SEMS group than the ES group. In addition, the ICU admission rate was significantly lower in the SEMS group $(11.4 \%, 4 / 35)$ than the ES group $(34.7 \%, 25 / 72)$, suggesting that the main advantages of stent placement were a reduced incidence of postoperative complications and shorter hospital stay. Other studies reported similar conclusions. One study reported shorter postoperative hospital stays and time to resume oral food intake in the SEMS group, suggesting better recovery from surgery [16].

The long-term prognosis of stent placement for MORC as a bridge to surgery was an important focus of the present study. Considering the differences in treatment methods and survival results, the PFS and OS rates were separately compared between the SEMS and ES groups in terms of stage IV disease and other stages. The results showed no significant differences in PFS and OS rates between patients with stage II and III colon cancer. A multicentre retrospective study also indicated that the long-term oncologic outcome of the SEMS group was similar or slightly better than that of the ES group among all patients with stage II or III colon cancer [21]. According to a meta-analysis of 11 studies, which included 1136 patients with left-sided or rightsided obstructive colon cancer, stenting as a bridge to surgery was oncologically comparable to ES with respect to OS, disease-free survival, and recurrence [22]. Moreover, Li et al. and Gianotti et al. reported improved survival of the SEMS group throughout the follow-up period [23, 24].
For patients with CRC, the liver is the most common site of metastasis and hepatic metastasis during the course of disease is the main cause of death [25, 26]. Of the 93 patients with stage II or III disease in the present study, liver metastasis occurred in eight (8.6\%) after surgery. In cases of synchronous CRC liver metastases (CRCLM), the prognosis of untreated patients is poor, as fewer than $30 \%$ had survived at 1 year and fewer than $5 \%$ at 5 years after diagnosis [27]. Surgical resection is the most effective treatment for CRCLM, as the 5-year survival rate after liver resection reportedly ranges from 44 to $57 \%[28,29]$. In the present study, 14 patients had right-sided colorectal obstructions with synchronous metastasis. In the SEMS group, six (95.7\%) of seven patients underwent resection of the primary tumour and the metastatic sites of the liver, while only one patient in the ES group underwent combined resection and the other seven underwent colectomy for severe obstruction. Thus, we inferred that SEMS improved the suitability of patients with stage IV disease for radical resection. Among the patients who underwent liver surgery, median survival was 42 months, which is comparable to the survival duration of 36 to 57 months in other reports [29, 30]. Based on these survival data of different treatment regimens, it is obvious that patients could benefit from resection of both the primary tumour and sites of metastasis.

There were several limitations to this study. First, in terms of baseline characteristics, SEMS was not employed in the cecum due to differences in tumour location. The main reason for this imbalance is that stent placement in the cecum of the right-sided colon is more technically challenging, as the stent should preferably extend beyond the stricture at both ends by $1.5-2 \mathrm{~cm}$. Of course, the results of the present study were limited by the relatively small number of patients, especially those with liver metastases, and the singlecentre retrospective study design. The small sample number was also a limit to the research on learning curve of right colon stenting. Nonetheless, future studies with larger numbers of subjects and longer followup periods are warranted.

\section{Conclusion}

In conclusion, stent placement as a bridge to surgery followed by selective surgery provides significant advantages in terms of short-term outcomes as compared to ES, but with comparable prognoses for patients with acute MORC. For patients with synchronous liver metastases, stent placement provides more opportunities for resection of the primary tumour and sites of metastasis in the liver, which can further improve survival. 


\section{Supplementary Information}

The online version contains supplementary material available at https://doi. org/10.1186/s12893-020-00993-4.

Additional file 1: Table S1. Characteristics of the surgical procedures and postoperative short-term outcomes after excluding tumors in the cecum.

\section{Abbreviations}

SEMS: Self-expandable metal stents; MORC: Malignant obstruction of rightsided colon; PFS: Progression-free survival; OS: Overall survival; ES: Emergency surgery; ICU: Intensive Care Unit; HR: Hazard ratio; CRC: Colorectal cancer; CT: Computed tomography; MODS: Multiple organ dysfunction syndrome; AHF: Acute heart failure; Cl: Confidence interval; TACE: Transcatheter arterial chemoembolization; ESGE: European Society of Gastrointestinal Endoscopy; CRCLM: CRC liver metastases.

\section{Acknowledgements}

Not applicable.

\section{Authors' contributions}

Conception and design: J-MX, Y-SZ. Acquisition of data: BL, Z-TL, QS, Z-PQ, DS, S-LC, AY, E-PX. Analysis and interpretation of the data: BL, L-QY, P-HZ, S-LC, $A Y, J-M X, Y-S Z$. Drafting of the article: BL, S-LC. Critical revision of the article for important intellectual content: S-LC, Z-TL. Final approval of the article: BL, S-LC, Z-TL, QS, Z-PQ, DS, AY, E-PX, L-QY, P-HZ, J-MX, Y-SZ. All authors read and approved the final manuscript.

\section{Funding}

This work was supported by grants from the National Natural Science Foundation of China (Grant no. 81672329), and the Dawn Program of the Shanghai Education Commission (Grant no. 18SG08). The funders had no role in the study design, data collection/analysis, decision to publish, or preparation of the manuscript.

\section{Availability of data and materials}

The datasets used and analysed during this study are available from the corresponding author upon reasonable request.

\section{Ethics approval and consent to participate}

This study was approved by the institutional review board of Zhongshan Hospital of Fudan University (Approval number 09-135). Written informed consent for treatment and use of their clinical data was obtained from all participants.

\section{Consent for publication}

Written informed consent for publication of their clinical details was obtained from all patients.

\section{Competing interests}

The authors have no competing interests to declare.

\section{Author details}

1 Endoscopy Center, Zhongshan Hospital of Fudan University, 180 Fenglin Road, Shanghai 200032, China. ${ }^{2}$ Endoscopy Research Institute of Fudan University, Shanghai 200032, China. ${ }^{3}$ Department of General Surgery, Zhongshan Hospital, Fudan University, Shanghai 200032, China.

Received: 4 June 2020 Accepted: 30 November 2020 Published online: 10 December 2020

\section{References}

1. Bray F, Ferlay J, Soerjomataram I, Siegel RL, Torre LA, Jemal A. Global cancer statistics 2018: GLOBOCAN estimates of incidence and mortality worldwide for 36 cancers in 185 countries. CA Cancer J Clin. 2018.

2. Cheynel N, Cortet M, Lepage C, Benoit L, Faivre J, Bouvier AM. Trends in frequency and management of obstructing colorectal cancers in a welldefined population. Dis Colon Rectum. 2007;50(10):1568-75.
3. Jullumstro E, Wibe A, Lydersen S, Edna TH. Colon cancer incidence, presentation, treatment and outcomes over 25 years. Colorectal Dis. 2011;13(5):512-8.

4. Winner M, Mooney SJ, Hershman DL, Feingold DL, Allendorf JD, Wright JD, et al. Incidence and predictors of bowel obstruction in elderly patients with stage IV colon cancer: a population-based cohort study. JAMA Surg. 2013:148(8):715-22.

5. van Hooft JE, Bemelman WA, Oldenburg B, Marinelli AW, Lutke Holzik MF, Grubben MJ, et al. Colonic stenting versus emergency surgery for acute left-sided malignant colonic obstruction: a multicentre randomised trial. Lancet Oncol. 2011;12(4):344-52.

6. Arezzo A, Balague C, Targarona E, Borghi F, Giraudo G, Ghezzo L, et al. Colonic stenting as a bridge to surgery versus emergency surgery for malignant colonic obstruction: results of a multicentre randomised controlled trial (ESCO trial). Surg Endosc. 2017;31(8):3297-305.

7. Spannenburg L, Sanchez Gonzalez M, Brooks A, Wei S, Li X, Liang X, et al. Surgical outcomes of colonic stents as a bridge to surgery versus emergency surgery for malignant colorectal obstruction: a systematic review and meta-analysis of high quality prospective and randomised controlled trials. Eur J Surg Oncol. 2020:46(8):1404-14.

8. Meisner S, Gonzalez-Huix F, Vandervoort JG, Goldberg P, Casellas JA, Roncero $\mathrm{O}$, et al. Self-expandable metal stents for relieving malignant colorectal obstruction: short-term safety and efficacy within 30 days of stent procedure in 447 patients. Gastrointest Endosc. 2011;74(4):876-84

9. Tekkis PP, Kinsman R, Thompson MR, Stamatakis JD, Association of Coloproctology of Great Britain I. The Association of Coloproctology of Great Britain and Ireland study of large bowel obstruction caused by colorectal cancer. Ann Surg. 2004;240(1):76-81.

10. Kobayashi H, Miyata H, Gotoh M, Baba H, Kimura W, Kitagawa Y, et al. Risk model for right hemicolectomy based on 19,070 Japanese patients in the National Clinical Database. J Gastroenterol. 2014:49(6):1047-55.

11. Yao LQ, Zhong YS, Xu MD, Xu JM, Zhou PH, Cai XL. Self-expanding metallic stents drainage for acute proximal colon obstruction. World J Gastroenterol. 2011;17(28):3342-6.

12. Ye LC, Liu TS, Ren L, Wei Y, Zhu DX, Zai SY, et al. Randomized controlled trial of cetuximab plus chemotherapy for patients with KRAS wildtype unresectable colorectal liver-limited metastases. J Clin Oncol. 2013:31(16):1931-8

13. von Elm E, Altman DG, Egger M, Pocock SJ, Gotzsche PC, Vandenbroucke JP, et al. The Strengthening the Reporting of Observational Studies in Epidemiology (STROBE) statement: guidelines for reporting observational studies. Lancet. 2007:370(9596):1453-7.

14. Campbell KL, Hussey JK, Eremin O. Expandable metal stent application in obstructing carcinoma of the proximal colon: report of a case. Dis Colon Rectum. 1997;40(11):1391-3.

15. Repici A, Adler DG, Gibbs CM, Malesci A, Preatoni P, Baron TH. Stenting of the proximal colon in patients with malignant large bowel obstruction: techniques and outcomes. Gastrointest Endosc. 2007;66(5):940-4.

16. Ji WB, Kwak JM, Kang DW, Kwak HD, Um JW, Lee SI, et al. Clinical benefits and oncologic equivalence of self-expandable metallic stent insertion for right-sided malignant colonic obstruction. Surg Endosc. 2017;31(1):153-8

17. Arezzo A, Passera R, Lo Secco G, Verra M, Bonino MA, Targarona E, et al. Stent as bridge to surgery for left-sided malignant colonic obstruction reduces adverse events and stoma rate compared with emergency surgery: results of a systematic review and meta-analysis of randomized controlled trials. Gastrointest Endosc. 2017;86(3):416-26.

18. Iversen LH, Bulow S, Christensen IJ, Laurberg S, Harling H, Danish Colorectal Cancer G. Postoperative medical complications are the main cause of early death after emergency surgery for colonic cancer. Br J Surg. 2008;95(8):1012-9.

19. Wang B, Lu S, Song Z, Li F, Ma J, Ma Y, et al. Comparison of clinical outcomes and pathological characteristics of self-expandable stent bridge to surgery and emergency surgery in obstructive colon cancer. Cancer Manag Res. 2020;12:1725-32.

20. Ormando VM, Palma R, Fugazza A, Repici A. Colonic stents for malignant bowel obstruction: current status and future prospects. Expert Rev Med Devices. 2019;16(12):1053-61.

21. Kye BH, Lee YS, Cho HM, Kim JG, Oh ST, Lee IK, et al. Comparison of long-term outcomes between emergency surgery and bridge to surgery 
for malignant obstruction in right-sided colon cancer: a multicenter retrospective study. Ann Surg Oncol. 2016;23(6):1867-74.

22. Matsuda A, Miyashita M, Matsumoto S, Matsutani T, Sakurazawa N, Takahashi $\mathrm{G}$, et al. Comparison of long-term outcomes of colonic stent as "bridge to surgery" and emergency surgery for malignant large-bowel obstruction: a meta-analysis. Ann Surg Oncol. 2015;22(2):497-504.

23. Li ZX, Wu XH, Wu HY, Chang WJ, Chang XJ, Yi T, et al. Self-expandable metallic stent as a bridge to elective surgery versus emergency surgery for acute malignant colorectal obstruction. Int J Colorectal Dis. 2016;31(3):561-70.

24. Gianotti L, Tamini N, Nespoli L, Rota M, Bolzonaro E, Frego R, et al. A prospective evaluation of short-term and long-term results from colonic stenting for palliation or as a bridge to elective operation versus immediate surgery for large-bowel obstruction. Surg Endosc. 2013;27(3):832-42.

25. Van Cutsem E, Nordlinger B, Adam R, Kohne CH, Pozzo C, Poston G, et al. Towards a pan-European consensus on the treatment of patients with colorectal liver metastases. Eur J Cancer. 2006;42(14):2212-21.

26. Sorski L, Melamed R, Levi B, Matzner P, Lavon H, Rosenne E, et al. Prevention of liver metastases through perioperative acute $\mathrm{CpG}-\mathrm{C}$ immune stimulation. Cancer Immunol Immunother. 2020;69(10):2021-31.
27. Manfredi S, Lepage C, Hatem C, Coatmeur O, Faivre J, Bouvier AM. Epidemiology and management of liver metastases from colorectal cancer. Ann Surg. 2006;244(2):254-9.

28. Morris EJ, Forman D, Thomas JD, Quirke P, Taylor EF, Fairley L, et al. Surgical management and outcomes of colorectal cancer liver metastases. Br J Surg. 2010;97(7):1110-8

29. Noren A, Eriksson HG, Olsson LI. Selection for surgery and survival of synchronous colorectal liver metastases; a nationwide study. Eur I Cancer 2016:53:105-14.

30. de Jong MC, Pulitano C, Ribero D, Strub J, Mentha G, Schulick RD, et al. Rates and patterns of recurrence following curative intent surgery for colorectal liver metastasis: an international multi-institutional analysis of 1669 patients. Ann Surg. 2009;250(3):440-8.

\section{Publisher's Note}

Springer Nature remains neutral with regard to jurisdictional claims in published maps and institutional affiliations.
Ready to submit your research? Choose BMC and benefit from:

- fast, convenient online submission

- thorough peer review by experienced researchers in your field

- rapid publication on acceptance

- support for research data, including large and complex data types

- gold Open Access which fosters wider collaboration and increased citations

- maximum visibility for your research: over $100 \mathrm{M}$ website views per year

At $\mathrm{BMC}$, research is always in progress.

Learn more biomedcentral.com/submissions 